\title{
Impact of sitagliptin combination therapy and hypoglycemia in Japanese patients with type 2 diabetes: a multi-center retrospective observational cohort study
}

\author{
Tomoyuki Saito ${ }^{1,2^{*}}$, Hirotoshi Ohmura', Shuko Nojiri ${ }^{3}$ and Hiroyuki Daida ${ }^{1}$
}

\begin{abstract}
Background: Patients with diabetes are at higher risk of developing polypharmacy because of the high frequency of comorbidities. There have been several reports on the hypoglycemic risk of the combination of hypoglycemic agents and other medications. This study aimed to investigate the hypoglycemic risk of drug-drug interaction between sitagliptin and other oral hypoglycemic agents or antihypertensive agents in Japanese patients with type 2 diabetes.

Methods: From January 2010 to March 2012, a total of 3247 patients were recruited and evaluated at outpatient clinics at Juntendo University Hospital, other satellite hospitals, and private clinics. This study was a sub-analysis of the Sitagliptin Registration Type 2 Diabetes-Juntendo Collaborating Project. Participants were limited to those treated with oral hypoglycemic agents, excluding insulin users, to investigate the association of the first hypoglycemic events with oral hypoglycemic agents or other medications within 6 months after starting sitagliptin. The factors related to the first hypoglycemic event were analyzed using Cox regression analysis.

Results: In total, 2956 patients with a mean age of $65.1 \pm 11.3$ years were included. A total of 46 hypoglycemic events (1.6\%) were observed. One patient had severe hypoglycemia followed by emergency transport to the hospital. Sitagliptin was not associated with hypoglycemia, but its combination with sulfonylurea (hazard ratio: 4.42, 95\% confidential interval: 1.36-14.42) or $\beta$-blocker (hazard ratio, 3.50, 95\% confidential interval: 1.54-7.96) was significantly associated with hypoglycemia.

Conclusions: The drug-drug interactions between sitagliptin and sulfonylurea or $\beta$-blocker likely increases the hypoglycemic risk in Japanese patients with type 2 diabetes. Pharmacists should consider potential adverse events from drug-drug interaction in type 2 diabetes with polypharmacy, particularly those who are managed by several doctors or clinics.
\end{abstract}

Keywords: Hypoglycemia, Dipeptidyl-peptidase IV inhibitors, Beta-blockers, Type 2 diabetes mellitus

\footnotetext{
* Correspondence: tomosai@juntendo.ac.jp

'Department of Cardiovascular Medicine, Juntendo University Graduate

School of Medicine, 2-1-1 Hongo, Bunkyo-Ku, Tokyo 113-8421, Japan

2Department of Pharmacy, Juntendo University Hospital, 3-1-3 Hongo, Bunkyo-Ku, Tokyo 113-8431, Japan

Full list of author information is available at the end of the article
}

(c) The Author(s). 2020 Open Access This article is licensed under a Creative Commons Attribution 4.0 International License, which permits use, sharing, adaptation, distribution and reproduction in any medium or format, as long as you give appropriate credit to the original author(s) and the source, provide a link to the Creative Commons licence, and indicate if changes were made. The images or other third party material in this article are included in the article's Creative Commons licence, unless indicated otherwise in a credit line to the material. If material is not included in the article's Creative Commons licence and your intended use is not permitted by statutory regulation or exceeds the permitted use, you will need to obtain permission directly from the copyright holder. To view a copy of this licence, visit http://creativecommons.org/licenses/by/4.0/ The Creative Commons Public Domain Dedication waiver (http://creativecommons.org/publicdomain/zero/1.0/) applies to the data made available in this article, unless otherwise stated in a credit line to the data. 


\section{Background}

The prevalence of type 2 diabetes (T2DM) has been markedly increasing worldwide in recent decades [1]. In Japan, approximately 10 million people have T2DM, and it is estimated that just as many people potentially have T2DM [2]. T2DM is associated with reduced quality of life (QOL) and shortened life expectancy associated with microvascular complications [3-9]. Therefore, the ultimate goals of T2DM management are to maintain QOL and to prolong life expectancy by preventing vascular complications [10].

It has been reported that maintaining good glycemic control reduces the risk of microvascular complications [11-14]. However, previous clinical trials have failed to show the effects of intensive glycemic control on reducing the incidence of macrovascular complications [12, 14-16]. According to the Action to Control Cardiovascular Risk in Diabetes (ACCORD) trial, intensive glucose-lowering therapy failed to reduce major cardiovascular events. Moreover, severe hypoglycemia with intensive therapy resulted in increased mortality [17]. Therefore, the prevention of hypoglycemia is an important issue in the treatment of diabetes.

Patients with T2DM are more likely to have metabolic disorders such as hypertension, dyslipidemia, underlying insulin resistance, and other comorbidities. However, optimal comprehensive risk management including glucose, lipid, and blood pressure control demonstrated beneficial effects on decreasing the incidence of both microvascular and macrovascular complications and even on all-cause mortality [18-20]. Consequently, these patients are generally treated with many pharmacological compounds, commonly referred as "polypharmacy" [21, 22]. With this type of treatment, patients generally are at a high risk for drug-drug interactions. Polypharmacy is one of the risk factors associated with hypoglycemia as well as a lower education level, ethnicity, irregular meals/malnutrition, insulin and sulfonylurea therapy, cognitive impairment, depression and frailty. Among patients with T2DM, diabetic complications are more frequent in those with hypertension than in those without hypertension [7, 23-25]. However, a few antihypertensive agents have also been associated with an increased incidence of hypoglycemia and an increased risk of cardiovascular events [26]. Therefore, it is necessary to clarify the effects of the combined use of each OHA and antihypertensive drugs on hypoglycemia within a clinical setting.

Thus, the present study aimed to investigate the risk of hypoglycemia related to drug-drug interaction between OHAs and antihypertensive agents in Japanese patients with T2DM as a sub-analysis from the Sitagliptin Registration Type 2 Diabetes-Juntendo Collaborating Project (SPIRITS-J).

\section{Methods}

\section{Setting and study cohort}

The SPIRITS-J study was a multi-center retrospective observational cohort study designed to evaluate the efficacy and safety of sitagliptin supplementation for over 6 months. Participants were Japanese patients with T2DM who were treated with diet and exercise, other OHA combination therapy, and/or insulin therapy. All procedures were conducted according to the 1964 Declaration of Helsinki revised in 2013 and the Ethical Standards of the Responsible Committee on Human Experimentation. From January 2010 to March 2012, a total of 3247 patients were recruited and evaluated at outpatient clinics at Juntendo University Hospital, other satellite hospitals, and private clinics. We conducted a sub-group analysis in 2956 patients with T2DM who were excluded from insulin treatment (Fig. 1). In a study conducted by the Japanese Society of Glucose and Diabetes to investigate severe hypoglycemia, insulin was responsible for approximately $60 \%$ of severe hypoglycemia in patients with T2DM [15]. Hypoglycemia was excluded from the analysis because it was significantly affected by insulin treatment. This study was enrolled in the UMINS clinical trial registry (UMIN 000004121).

\section{Data collection}

Data were collected at four time points within 6 months after the initiation of sitagliptin (baseline, 1, 3, and 6 months). Baseline clinicodemographic data of all the patients enrolled in this study were collected, including age, sex, body mass index (BMI), diabetes duration, diabetes-related complications, medical history, lipid profile, random blood glucose, HbA1c, serum creatinine, and ingredient of medication for hypertension and diabetes. Blood test results were obtained from the medical records. Glucose and $\mathrm{HbA1c}$ were measured with standard techniques. The value of HbA1c (\%) was estimated as the National Glycohemoglobin Standardization Program (NGSP) equivalent value (\%) calculated using the formula HbA1c (\%) = HbA1c (Japan Diabetes Society) (\%) $+0.4 \%$ [16]. The estimated glomerular filtration rate (eGFR) was calculated using the following formula: eGFR $\left(\mathrm{mL} / \mathrm{min} / 1.73 \mathrm{~m}^{2}\right)=194 \times$ age $-0.287 \times$ serum creatinine -0.1094 ( $\times 0.739$ for women $)$ [27].

\section{Definition of hypoglycemia}

We collected information on the first hypoglycemic event from patient self-report, medical records, and blood analysis from medical examinations with a blood glucose level of $\leq 60 \mathrm{mg} / \mathrm{dL}$. Therefore, it includes subjective symptoms determined to be caused by hypoglycemia regardless of blood glucose level. The participants did not conduct self-monitoring of blood glucose (SMBG) because in the Japanese healthcare system, 


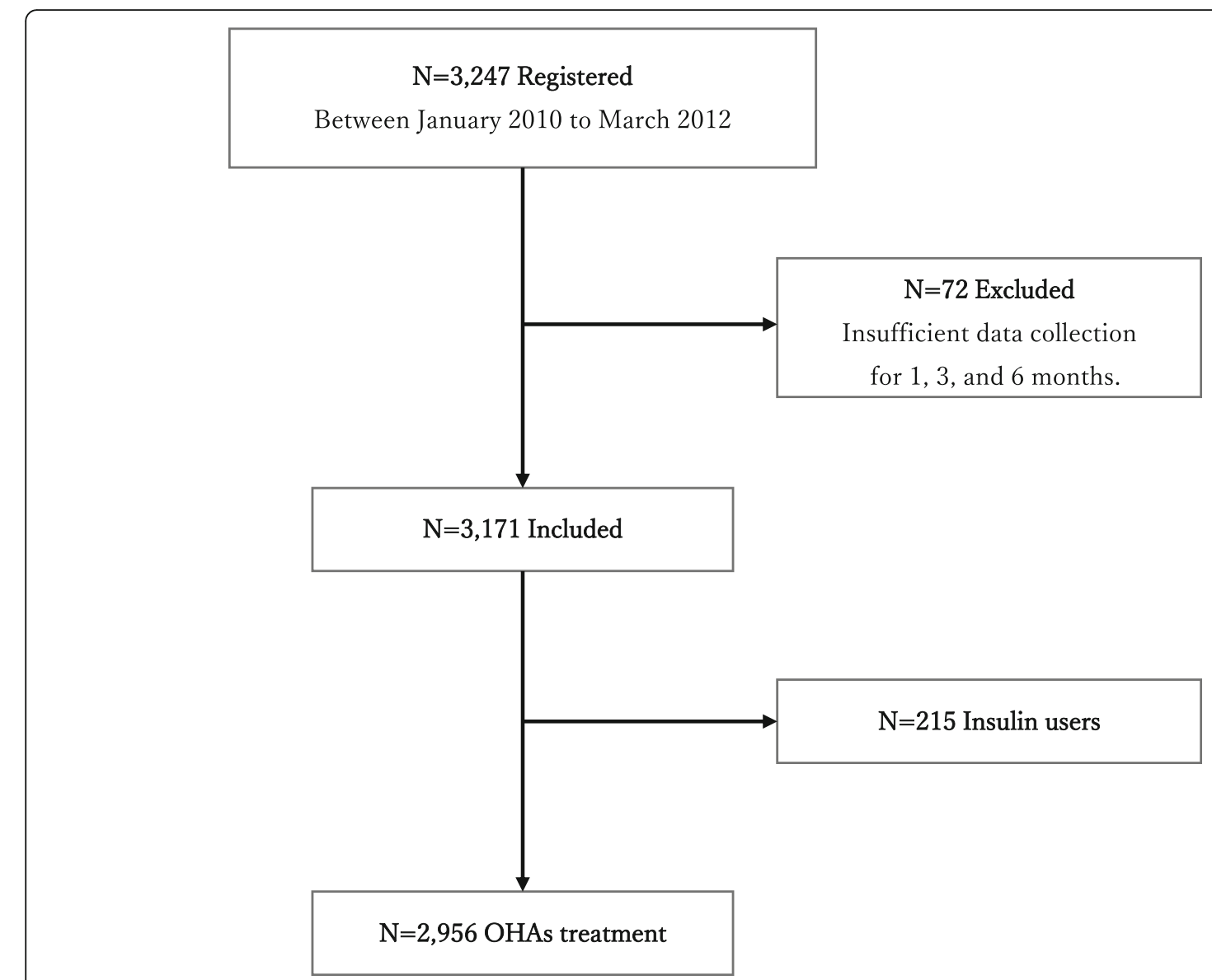

Fig. 1 Patient selection flow diagram in the observational cohort study. OHAs, oral hypoglycemic agents

SMBG is covered by insurance only in insulin users. Severe hypoglycemia represented hypoglycemic episodes that required the attention and assistance of another person.

\section{Definition of diabetic microvascular complications}

Retinopathy was defined as a progression from the absence of retinopathy to nonproliferative retinopathy or proliferative retinopathy, progression from nonproliferative retinopathy to proliferative retinopathy, or loss of vision due to retinopathy. Nephropathy is the progression from normal albuminuria to macroalbuminuria or from microalbuminuria to macroalbuminuria; an increase in serum creatinine concentration at least twice the study baseline; or end-stage renal failure, neuropathy, or neuropathy unrelated to peripheral neuropathy or spinal stenosis.

\section{Statistical analysis}

Results are presented as mean \pm standard deviation (SD) or percentage (\%). The HbA1c values observed at the four time points were calculated using a mixed-effects model to account for repeated measurements of participants and the random effects of observations. Pvalue was calculated using type III tests of fixed effects. Differences between baseline data and any observation points were examined for statistical significance using the Student's t-test. Categorical variables were compared using the Chi-squared test and presented as absolute frequencies with percentages. The factors associated with hypoglycemic events were examined using Cox Regression analysis. A two-sided $P$-value of $<0.05$ was considered statistically significant. The hazard ratio (HR) in cohort studies is positively correlated to the cumulative disease incidence [28]. Hence, it is important that enough events occur during the analysis period. In our previous study, we reported that blood glucose levels decreased significantly during the first month after the start of treatment with sitagliptin [6]. In addition, it has been found that hypoglycemia tends to increase during that period. Therefore, the Cox regression model was used considering the dynamic characteristics of the expected distribution. Moreover, it was confirmed that the proportional hazards in the Cox regression model were appropriate. All analyses were performed using SAS Ver. 9.4 (SAS Institute Inc., Cary, NC, USA). 


\section{Results}

\section{Baseline clinicodemographic characteristics}

Table 1 demonstrates the baseline clinicodemographic characteristics of the study patients. The mean T2DM duration was $10.2 \pm 7.5$ years, and the mean HbA1c level was $7.8 \pm 1.2 \%$. The mean age was $65.1 \pm 11.3$ years. In total, 459 (15.6\%) patients had a history of coronary artery disease, and only approximately $15 \%$ of patients had at least one diabetic microvascular complication.

Table 2 demonstrates the usage of OHAs and antihypertensive agents in this study. Overall, 764 (25.5\%) patients had treatment with sitagliptin monotherapy. The most common class of OHAs combined with sitagliptin was sulfonylurea (SU) (50.4\%), followed by biguanide (39.5\%), thiazolidinedione (TZD) (22.7\%), alpha-glucosidase inhibitors ( $\alpha$-GI) $(13.5 \%)$, and glinides $(2.0 \%)$. For the antihypertensive agents, angiotensinconverting enzyme inhibitors/angiotensin II receptor blockers (59.3\%) and calcium channel blockers (46.9\%) were the most commonly prescribed in this study.
Meanwhile, $\beta$-blockers (BB) (13.6\%) and diuretics (9.7\%) was less frequently prescribed.

\section{Characteristics of the patients with hypoglycemia}

A total of 46 hypoglycemic events (1.6\%) were observed during the first 6 months after starting sitagliptin. One patient had severe hypoglycemia followed by emergency transport to the hospital. The patients with hypoglycemic events had a significantly higher number of combined OHAs $(2.1 \pm 1.0$ vs. $1.3 \pm 1.0, p<0.0001)$ and significantly lower BMI $(23.5 \pm 3.9$ vs. $25.1 \pm 4.3, p=0.0228)$ and plasma levels of UA $(4.6 \pm 1.4$ vs. $5.2 \pm 1.6, p=0.0325)$ (Table 1). There was no significant difference in the duration of T2DM, although it tended to be longer in patients with hypoglycemic events $(12.4 \pm 7.2$ vs. $10.2 \pm 7.5$, $p=0.0784$ ). In addition, the prevalence of macrovascular and microvascular complications was not significantly different between the two groups. Regarding the OHAs and anti-hypertensive agents, the usage of SU, TZD, $\alpha-G I$,

Table 1 Baseline characteristics of the study subjects

\begin{tabular}{|c|c|c|c|c|}
\hline & OHA patients $(n=2956)$ & non-hypoglycemia $(N=2910)$ & hypoglycemia $(N=46)$ & $P$-value \\
\hline Sex (male\%) & $1772(59.9 \%)$ & $1749(60.1 \%)$ & $23(50.0 \%)$ & 0.1653 \\
\hline Age & $65.1 \pm 11.3$ & $65.1 \pm 11.3$ & $65.9 \pm 8.6$ & 0.5311 \\
\hline$B M I^{\mathrm{a}}$ & $25.0 \pm 4.3$ & $25.1 \pm 4.3$ & $23.5 \pm 3.9$ & 0.0228 \\
\hline Smoking status & & & & 0.6357 \\
\hline Current users & $614(23.5 \%)$ & $603(23.5 \%)$ & $11(26.8 \%)$ & \\
\hline Past users & $531(20.3 \%)$ & $525(20.5 \%)$ & $6(14.6 \%)$ & \\
\hline Never users & $1463(56.1 \%)$ & $1439(56.1 \%)$ & $24(58.5 \%)$ & \\
\hline Diabetic duration & $10.2 \pm 7.5$ & $10.2 \pm 7.5$ & $12.4 \pm 7.2$ & 0.0784 \\
\hline \multicolumn{5}{|l|}{ Comorbidity } \\
\hline Coronary artery diseases & $9(0.3 \%)$ & $9(0.3 \%)$ & $0(0.0 \%)$ & 0.7081 \\
\hline Cerebrovascular diseases & $276(9.4 \%)$ & $273(9.4 \%)$ & $3(6.7 \%)$ & 0.5295 \\
\hline \multicolumn{5}{|c|}{ Diabetic microvascular complications } \\
\hline Retinopathy & $418(14.2 \%)$ & $413(14.3 \%)$ & $5(11.1 \%)$ & 0.5493 \\
\hline Neuropathy & $345(11.7 \%)$ & $339(11.7 \%)$ & $6(13.3 \%)$ & 0.7350 \\
\hline Nephropathy & $514(17.4 \%)$ & $508(17.5 \%)$ & $6(13.3 \%)$ & 0.4619 \\
\hline \multicolumn{5}{|l|}{ Medication } \\
\hline Number of combined OHA & $1.3 \pm 1.0$ & $1.3 \pm 1.0$ & $2.1 \pm 1.0$ & $<.0001$ \\
\hline \multicolumn{5}{|l|}{ Clinical data } \\
\hline HbA1c (NGSP) (\%) & $7.8 \pm 1.2$ & $7.8 \pm 1.2$ & $7.9 \pm 1.2$ & 0.4905 \\
\hline eGFR ${ }^{b}$ & $76.6 \pm 22.9$ & $76.7 \pm 22.9$ & $72.7 \pm 22.6$ & 0.2649 \\
\hline $\mathrm{HDL}-\mathrm{C}$ & $55.6 \pm 15.0$ & $55.5 \pm 15.0$ & $56.2 \pm 14.9$ & 0.8018 \\
\hline TC & $193.8 \pm 37.1$ & $193.9 \pm 37.2$ & $190.4 \pm 27.6$ & 0.5306 \\
\hline TG & $155.0 \pm 127.2$ & $155.2 \pm 127.8$ & $140.8 \pm 87.5$ & 0.3002 \\
\hline Uric acid & $5.2 \pm 1.6$ & $5.2 \pm 1.6$ & $4.6 \pm 1.4$ & 0.0325 \\
\hline
\end{tabular}

BMI Body-mass index, OHAs Oral hypoglycemic agents, eGFR Estimated glomerular filtration rate, HDL-C High-density lipoprotein cholesterol, TC Total cholesterol, TG Triglyceride

${ }^{\text {a }}$ The body-mass index is body weight in kilograms divided by the square of height in meters

${ }^{\mathrm{b}}$ The estimated GFR was calculated using the modified Modification of Diet in Renal Disease (MDRD) formula 
Table 2 Use of oral antidiabetic agents in the study subjects stratified by hypoglycemic event

\begin{tabular}{lllll}
\hline Drugs & Overall population & Non-hypoglycemia & \multicolumn{1}{l}{$\begin{array}{l}\text { Hypoglycemia } \\
\text { N (\%) }\end{array}$} \\
\hline SU & N (\%) & N (\%) & $40(87.0)$ & $\mathbf{<}$ \\
TZD & $1468(50.4)$ & $1428(49.8)$ & $16(34.8)$ & $\mathbf{0 . 0 0 0 1}$ \\
Glinide & $662(22.7)$ & $646(22.5)$ & $0(0.0)$ & $\mathbf{0 . 0 4 9 0}$ \\
AGl & $59(2.0)$ & $59(2.1)$ & $15(32.6)$ & $\mathbf{0 . 0 0 0 1}$ \\
Biguanide & $393(13.5)$ & $378(13.2)$ & $27(58.7)$ & $\mathbf{0 . 0 0 7 4}$ \\
B-blocker & $1152(39.5)$ & $1125(39.2)$ & $11(27.5)$ & $\mathbf{0 . 0 0 9 8}$ \\
Diuretic & $318(13.6)$ & $307(13.4)$ & $4(10.0)$ & 0.9440 \\
ACE/ARB & $226(9.7)$ & $222(9.7)$ & $22(55.0)$ & 0.5814 \\
CCB & $1384(59.3)$ & $1362(59.3)$ & $17(42.5)$ & 0.5723 \\
\hline
\end{tabular}

SU Sulfonylurea, TZD Thiazolidinedione, $A G I$ Alpha-glucosidase inhibitors, ACE-I Angiotensin-converting enzyme inhibitors, $A R B$ Angiotensin II receptor blocker, CCB Calcium channel blocker

${ }^{*}$ Chi-squared tests were used in the analyses of categorical variables

biguanide, and $\mathrm{BB}$ was significantly higher in patients with hypoglycemia.

In multivariate Cox regression model for the risk of hypoglycemia adjusted for sex, age, BMI, prescription number of OHAs, and eGFR, low BMI (HR: 0.86, 95\% confidential interval (CI): 0.78-0.95), low uric acid (HR: 0.67, 95\% CI: 0.49-0.90), use of SU (HR: 4.42, 95\% CI: 1.36-14.42), and BB (HR: 3.50, 95\% CI: 1.54-7.96) remained to be independent risk factors for hypoglycemia (Table 3 ).

\section{Discussion}

The present study investigated the risk of hypoglycemia from drug-drug interactions between sitagliptin and other OHAs or antihypertensive agents in Japanese patients with T2DM. In the SPIRITS-J study, the incidence of hypoglycemia in sitagliptin treatment combined with other OHAs was $1.6 \%$. This result suggested the safety of sitagliptin as monotherapy or in combination with other OHAs in Japanese patients with T2DM. However, the multivariate Cox regression model demonstrated that the use of $\mathrm{SU}$ or $\mathrm{BB}$ were independent risk factors for hypoglycemia.

We have already reported that the risk of hypoglycemia associated with DPP-IV inhibitors is low, and that the risk increased when combined with SU. However, there are not enough reports on the hypoglycemic risk associated with drug combinations other than OHAs in patients with diabetes who have many complications. In particular, we investigated the drug-drug interactions with antihypertensive agents as a sub-analysis of SPIRITS-J.

Although maintaining good glycemic control reduces the risk of microvascular complications, intensive

Table 3 Multivariate Cox regression model for hypoglycemia risk

\begin{tabular}{|c|c|c|c|c|c|c|}
\hline & No. of cases & Person-years & Incidence rate per 100 population & $\mathrm{HR}$ & $95 \% \mathrm{Cl}$ & $P$-value \\
\hline \multicolumn{7}{|l|}{ Sitagliptin } \\
\hline monotherapy & 3 & 378 & 0.8 & 1.00 & & \\
\hline$+S U$ & 40 & 718 & 5.6 & 4.42 & $(1.36-14.42)$ & 0.014 \\
\hline$+\mathrm{TZD}$ & 16 & 326 & 4.9 & 0.55 & $(0.23-1.34)$ & 0.189 \\
\hline+ GLINIDE & 0 & 29 & 0.0 & & & \\
\hline$+A G l$ & 15 & 193 & 7.8 & 0.90 & $(0.37-2.22)$ & 0.820 \\
\hline+ BIGUANIDE & 27 & 566 & 4.8 & 0.83 & $(0.35-2.01)$ & 0.685 \\
\hline \multicolumn{7}{|c|}{ Antihypertensive agents } \\
\hline$+\beta$-blocker & 11 & 157 & 7.0 & 3.50 & $(1.54-7.96)$ & 0.003 \\
\hline + Diuretic & 4 & 111 & 3.6 & 1.67 & $(0.56-4.96)$ & 0.359 \\
\hline$+\mathrm{ACE} / \mathrm{ARB}$ & 22 & 681 & 3.2 & 0.91 & $(0.42-1.97)$ & 0.819 \\
\hline$+C C B$ & 17 & 541 & 3.1 & 0.97 & $(0.45-2.11)$ & 0.942 \\
\hline
\end{tabular}

Adjusted for sex, age, BMI, number of combined OHAs, and eGFR

SU sulfonylurea, TZD Thiazolidinedione, $A G$ I Alpha-glucosidase inhibitors, ACE-I Angiotensin-converting enzyme inhibitors, $A R B$ Angiotensin II receptor blocker, CCB Calcium channel blocker, $H R$ Hazard ratio, $\mathrm{Cl}$ Confidence interval 
glycemic control in the ACCORD trial resulted in increased all-cause and cardiovascular mortalities [18]. A possible explanation is that intensive glycemic control increased the risk of hypoglycemia and consequently increased the risk of major vascular events and death. Therefore, appropriate glycemic control without hypoglycemic events is important for preventing major cardiovascular events in patients with T2DM.

$\mathrm{SU}$ is widely used to treat T2DM because it the lowers blood glucose levels by releasing insulin from beta cells in the pancreas [29]. DPP-4 inhibitors stimulate insulin secretion, suppress glucagon secretion, and reduce gastric emptying in a glucose-dependent manner [30]. Although severe hypoglycemia has been reported even with the single usage of SU [31], a meta-analysis of combination therapy efficacy of DPP-4 inhibitors with SU in patients with T2DM showed that the risk of hypoglycemia was increased by approximately $50 \%$ [32]. Therefore, the Japan Association for Diabetes Education and Care has recommended that decreasing the SU dosage should be considered in case of concomitant use with DPP-4 inhibitors [33]. The Trial Evaluating Cardiovascular Outcomes with Sitagliptin (TECOS) study recently reported that the combination of sitagliptin and SU did not increase the risk for severe hypoglycemia [34]. In our study, only one patient had severe hypoglycemia, but the concomitant use of SU with sitagliptin was an independent risk factor for hypoglycemia.

Polypharmacy is common in patients with T2DM because they often have co-morbidities; thus, it is necessary to consider the effect of hypoglycemia from drugdrug interactions [35]. Both hypertension and coronary artery disease (CAD) are frequent comorbidities in patients with T2DM. Moreover, diabetic complications are more frequent in T2DM patients with hypertension than in T2DM patients without hypertension [24, 25]. The efficacy of $\mathrm{BB}$, which is one of the more popular antihypertensive agents, for preventing major cardiovascular events and improving prognosis has been established in patients with $\mathrm{CAD}[36,37]$. However, the benefit of $\mathrm{BB}$ in patients with T2DM has been controversial because $\mathrm{BB}$ is known to be associated with a risk for severe hypoglycemia [38]. In a post-hoc analysis of the ACCORD study, the use of $\mathrm{BB}$ in patients with T2DM was associated with not only the incidence of severe hypoglycemia, but also increased risk for cardiovascular events even in patients with CAD [36, 37]. Meanwhile, in patients with T2DM and atherosclerotic cardiovascular disease enrolled in the TECOS trial, which evaluated the effect of sitagliptin on cardiovascular outcomes, BB use was not associated with a risk for severe hypoglycemia but also was not associated with reduction of cardiovascular risk [39]. A recent meta-analysis reported that BB therapy in T2DM patients with stable
CHD is associated with higher mortality [40]. This is supported by our findings that BB therapy in T2DM more likely increases the risk of hypoglycemia, consequently increasing the risk of major adverse events. Again, the benefit of $\mathrm{BB}$ in patients with T2DM remains unclear.

Insulin, SU, and alcohol are common causes of druginduced hypoglycemia, but hypoglycemia occurs in around $10 \%$ of cases without the use of these drugs [41]. Among the $10 \%$ of alternate causes of drug-induced hypoglycemia, diuretics, BB, sympathomimetics, corticosteroids, and sex hormones are frequently reported. Carbohydrate metabolism may be adversely affected in patients with hypoglycemia, especially in those with diabetes or impaired glucose tolerance [42]. There are frequent reports that $\mathrm{BB}$ affect hypoglycemia, suggesting that they affect liver and kidney function through $\beta$ receptors [41].

The combination of BB and DPP-IV inhibitors increases the risk of hypoglycemia, which can be explained by two factors. First, BB has been reported to mask the symptoms of hypoglycemia by reducing peripheral antiadrenergic effects $[38,43]$. However, in the ACCROD trial, BB was reported to increase hypoglycemic events [26]. In our study, hypoglycemia also increased in patients using $\mathrm{BB}$. The fact that $\mathrm{BB}$ did not mask hypoglycemic symptoms may be related to $\beta$-receptor subtypes. Cardiac muscle has a large distribution of $\beta 1$ receptors, and skeletal muscle has $\beta 3$ receptors [44]. Therefore, since BBs used in recent years comprise several selective $\beta 1$ receptors, it is difficult to mask hypoglycemic symptoms with the drugs. Frequently used carvedilol exhibits both nonselective $\beta$-blocking and weak $\alpha$-receptor blocking effects; however, carvedilol has a weak $\beta 3$ receptor blocking effect [45]. Second, selective $\beta 2$-blockers suppress glycogen degradation and can counter act hypoglycemia owing to their effects on the liver and muscles [46]. Furthermore, $\beta$-receptor blockade suppresses glucagon secretion due to antiadrenergic action [47]. There is currently no clinical basis for these pharmacological actions, and clinical verification is needed in the future.

Our study has some limitations. First, this was an observational study with no randomization and may have selection bias. Therefore, the results of this study should be interpreted cautiously. Second, there was little information about lifestyle, diet and exercise therapy, drug adherence, and confounding effects of other medications. Furthermore, information on the proportion and doses of OHAs and BB at 6 months was lacking. Third, laboratory tests were not standardized throughout the study. Fourth, the type of each drug, particularly, the type of $\mathrm{BB}$, could not be identified. Among $\mathrm{BB}$ types, non-vasodilating $\mathrm{BB}$ has been suggested to be associated 
with hyperglycemia, while vasodilating $\mathrm{BB}$ is associated with hypoglycemia [48]. Further prospective randomized studies are needed to elucidate the benefits and disadvantages of $\mathrm{BB}$ therapy in patients with T2DM.

\section{Conclusion}

The drug-drug interaction between sitagliptin and sulfonylurea or $\beta$-blocker likely increases the hypoglycemic risk in Japanese patients with type 2 diabetes. Pharmacists should consider potential adverse events from drug-drug interactions in patients with T2DM with polypharmacy, particularly those managed by several doctors or clinics.

\section{Abbreviations \\ T2DM: Type 2 diabetes; QOL: Quality of life; ACCORD: Action to Control Cardiovascular Risk in Diabetes study; GLP-1: Glucagon-like peptide-1; GIP: Glucose-dependent insulinotropic polypeptide; OHAs: Oral hypoglycemic agents; HbA1c: Hemoglobin A1c; J-DOIT 3: The Japan Diabetes Optimal Integrated Treatment study; SPIRITS-J: The Sitagliptin Registration Type 2 Diabetes-Juntendo Collaborating Project; BMI: Body mass index; NGSP: The National Glycohemoglobin Standardization Program; eGFR: The estimated glomerular filtration rate; SMBG: Self-monitoring of blood glucose; SD: Standard deviation; SU: Sulfonylurea; \\ TZD: Thiazolidinedione; a-Gl: alpha-glucosidase inhibitors; BB: $\beta$-blockers; HR: Hazard ratio; TECOS: The Trial Evaluating Cardiovascular Outcomes with Sitagliptin study; CAD: Coronary artery disease}

\begin{abstract}
Acknowledgments
The authors would like to thank Ms. Keiko Wakana, Shoko Abukawa, Rinako Suga, Mayumi Fukuda, Atsuko Shiratori, and Yukari Nitta; Mr. Hiroshi Kitagawa and Genichiro Okazaki (Department Center for Lifetime Cancer Education, Juntendo University Graduate School of Medicine); and Ms. Megumi Matsumoto (Department of Cardiovascular Medicine) for their technical support. We also thank the participants of the study and Editage (www. editage.jp) for English language editing.
\end{abstract}

\section{Authors' contributions}

Authors' contributions Mr. Tomoyuki Saito designed the study, and wrote the initial draft of the manuscript. Dr. Hirotoshi Ohmura and Dr. Shuko Nojiri contributed to analysis and interpretation of data, and assisted in the preparation of the manuscript. All other authors have contributed to data collection and interpretation, and critically reviewed the manuscript. All authors approved the final version of the manuscript, and agree to be accountable for all aspects of the work in ensuring that questions related to the accuracy or integrity of any part of the work are appropriately investigated and resolved.

\section{Funding}

Financial support for this study was provided by the Waksman Foundation, Clinical Research Center, Juntendo University Graduate School of Medicine, and Center for Lifetime Cancer Education, Juntendo University Graduate School of Medicine. These centers received research funds from MSD, Daiichi Sankyo Inc., Novartis Pharmaceuticals, ONO Pharmaceutical Co., and Kyowa Hakko Kirin Co. The authors funded the article processing charges for this publication.

\section{Availability of data and materials}

The datasets generated during and/or analyzed during the current study are available from the corresponding author on reasonable request.

\section{Ethics approval and consent to participate}

All procedures performed in this study, including human participants, complied with the ethical standards of the Institutional Research Committee (Juntendo Clinical Research and Testing Center of Juntendo University Hospital) and the 1964 Declaration of Helsinki and subsequent amendments or equivalent. Informed consent was obtained from all individual participants included in the study.

\section{Consent for publication}

Not applicable.

\section{Competing interests}

Hirotoshi Ohmuara has received lecture fees from Takeda Pharmaceutical Co., MSD K.K., AstraZeneca K.K., and Shionogi \& Co. Ltd. and research funds from Pfizer Co., MSD K.K., and Takeda Pharmaceutical Co. Ltd. Hiroyuki Daida has received lecture fees from AstraZeneca K.K., MSD K.K., Kowa Pharmaceutical Company Ltd., Sanofi-Aventis K.K., GlaxoSmithKline K.K., Shionogi \& Co. Ltd., Daiichi-Sankyo Company, Limited, Takeda Pharmaceutical Co. Ltd., Mitsubishi Tanabe Pharma Corp., Pfizer Co. Ltd., and Astellas Pharma Inc. and research funds from Takeda Pharmaceutical Co. Ltd., Bristol-Myers Squibb Company, Nippon Boehringer Ingelheim Co. Ltd., Astellas Pharma Inc., Novartis Pharma K.K., MSD K.K., Sanofi-Aventis K.K., Otsuka Pharmaceutical Co. Ltd., Dainippon Sumitomo Pharma Co. Ltd., Pfizer Co. Ltd., Kowa Pharmaceutical Company Ltd., Shionogi \& Co. Ltd., AstraZeneca K.K., Teijin Limited, and Morinaga Milk Industry Co. Ltd. Tomoyuki Saito and Shuko Nojiri have nothing to declare.

\section{Author details}

${ }^{1}$ Department of Cardiovascular Medicine, Juntendo University Graduate School of Medicine, 2-1-1 Hongo, Bunkyo-Ku, Tokyo 113-8421, Japan. ${ }^{2}$ Department of Pharmacy, Juntendo University Hospital, 3-1-3 Hongo,

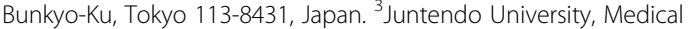
Technology Innovation Center, 3-1-3 Hongo, Bunkyo-Ku, Tokyo 113-8431, Japan.

Received: 1 March 2020 Accepted: 11 May 2020

Published online: 04 June 2020

\section{References}

1. Cho NH, Shaw JE, Karuranga S, Huang Y, da Rocha Fernandes JD, Ohlrogge AW, et al. IDF diabetes atlas: global estimates of diabetes prevalence for 2017 and projections for 2045. Diabetes Res Clin Pract. 2018;138:271-81. https://doi.org/10.1016/j.diabres.2018.02.023.

2. The Ministry of Health LaW. The National Health and nutrition survey; 2017. https://www.mhlw.go.jp/stf/houdou/0000177189.html.

3. Nathan DM, Genuth S, Lachin J, Cleary P, Crofford O, Davis M, et al. The effect of intensive treatment of diabetes on the development and progression of long-term complications in insulin-dependent diabetes mellitus. N Engl J Med. 1993;329:977-86. https://doi.org/10.1056/ NEJM199309303291401.

4. UK Prospective Diabetes Study (UKPDS) Group. Intensive blood-glucose control with sulphonylureas or insulin compared with conventional treatment and risk of complications in patients with type 2 diabetes (UKPDS 33). Lancet. 1998:352:837-53.

5. Eldor R, Raz I. The individualized target HbA1c: a new method for improving macrovascular risk and glycemia without hypoglycemia and weight gain. Rev Diabet Stud. 2009;6:6-12. https://doi.org/10.1900/RDS 2009.6.6.

6. Ohmura H, Mita T, Taneda Y, Sugawara M, Funayama H, Matsuoka J, et al. Efficacy and safety of sitagliptin in Japanese patients with type 2 diabetes. J Clin Med Res. 2015;7:211-9. https://doi.org/10.14740/jocmr1983w.

7. Modan M, Halkin H, Almog S, Lusky A, Eshkol A, Shefi M, et al. Hyperinsulinemia. A link between hypertension obesity and glucose intolerance. J Clin Invest. 1985;75:809-17. https://doi.org/10.1172/JCl111776.

8. UK Prospective Diabetes Study Group. Efficacy of atenolol and captopril in reducing risk of macrovascular and microvascular complications in type 2 diabetes: UKPDS 39. BMJ (Clinical research ed). 1998:317:713-20.

9. UK Prospective Diabetes Study Group. Tight blood pressure control and risk of macrovascular and microvascular complications in type 2 diabetes: UKPDS 38. BMJ (Clinical research ed). 1998:317:703-13.

10. Haneda M, Noda M, Origasa H, Noto H, Yabe D, Fujita Y, et al. Japanese clinical practice guideline for diabetes 2016. J Diabetes Investig. 2018;9:657-97. https://doi.org/10.1111/jdi.12810.

11. Miyazaki Y, Murakami H, Hirata A, Fukuoka M, Masuda A, Ura N, et al. Effects of the angiotensin converting enzyme inhibitor temocapril on insulin 
sensitivity and its effects on renal sodium handling and the pressor system in essential hypertensive patients. Am J Hypertens. 1998;11:962-70.

12. Paolisso G, Tagliamonte MR, Gambardella A, Manzella D, Gualdiero P, Varricchio $\mathrm{G}$, et al. Losartan mediated improvement in insulin action is mainly due to an increase in non-oxidative glucose metabolism and blood flow in insulinresistant hypertensive patients. J Hum Hypertens. 1997;11:307-12.

13. limura O, Shimamoto K, Matsuda K, Masuda A, Takizawa H, Higashiura K, et al. Effects of angiotensin receptor antagonist and angiotensin converting enzyme inhibitor on insulin sensitivity in fructose-fed hypertensive rats and essential hypertensives. Am J Hypertens. 1995;8:353-7.

14. Jarred G, Kennedy RL. Therapeutic perspective: starting an angiotensinconverting enzyme inhibitor or angiotensin II receptor blocker in a diabetic patient. Ther Adv Endocrinol Metab. 2010;1:23-8. https://doi.org/10.1177/ 2042018810369437.

15. Namba M, Iwakura $T$, Nishimura $R$, Akazawa $K$, Matsuhisa M, Atsumi $Y$, et al. The current status of treatment-related severe hypoglycemia in Japanese patients with diabetes mellitus: a report from the committee on a survey of severe hypoglycemia in the Japan diabetes society. J Diabetes Investig. 2018;9:642-56. https://doi.org/10.1111/jdi.12790.

16. Seino Y, Nanjo K, Tajima N, Kadowaki T, Kashiwagi A, Araki E, et al. Report of the committee on the classification and diagnostic criteria of diabetes mellitus. J Diabetes Investig. 2010;1:212-28. https://doi.org/10.1111/j.20401124.2010.00074.x

17. Gerstein HC, Miller ME, Byington RP, Goff DC, Bigger JT, Buse JB, et al. Effects of intensive glucose lowering in type 2 diabetes. N Engl J Med. 2008; 358:2545-59. https://doi.org/10.1056/NEJMoa0802743.

18. Gaede $\mathrm{P}$, Lund-Andersen $\mathrm{H}$, Parving $\mathrm{HH}$, Pedersen $\mathrm{O}$. Effect of a multifactorial intervention on mortality in type 2 diabetes. N Engl J Med. 2008:358:580-91. https://doi.org/10.1056/NEJMoa0706245.

19. Gaede $P$, Vedel $P$, Larsen $N$, Jensen GV, Parving HH, Pedersen $O$. Multifactorial intervention and cardiovascular disease in patients with type 2 diabetes. N Engl J Med. 2003;348:383-93. https://doi.org/10.1056/ NEJMoa021778.

20. Ueki K, Sasako T, Okazaki Y, Kato M, Okahata S, Katsuyama H, et al. Effect of an intensified multifactorial intervention on cardiovascular outcomes and mortality in type 2 diabetes (J-DOIT3): an open-label, randomised controlled trial. Lancet Diabetes Endocrinol. 2017;5:951-64. https://doi.org/10.1016/ S2213-8587(17)30327-3.

21. Austin RP. Polypharmacy as a risk factor in the treatment of type 2 diabetes. Diabetes Spectrum. 2006;19:13-6. https://doi.org/10.2337/diaspect.19.1.13.

22. Alwhaibi M, Balkhi B, Alhawassi TM, Alkofide $H$, Alduhaim N, Alabdulali R, et al. Polypharmacy among patients with diabetes: a cross-sectional retrospective study in a tertiary hospital in Saudi Arabia. BMJ Open. 2018;8: e020852. https://doi.org/10.1136/bmjopen-2017-020852.

23. Henry P, Thomas F, Benetos A, Guize L. Impaired fasting glucose, blood pressure and cardiovascular disease mortality. Hypertension (Dallas, Tex 1979). 2002;40:458-63. https://doi.org/10.1161/01.hyp.0000032853.95690.26.

24. Kengne AP, Patel A, Barzi F, Jamrozik K, Lam TH, Ueshima H, et al. Systolic blood pressure, diabetes and the risk of cardiovascular diseases in the AsiaPacific region. J Hypertens. 2007;25:1205-13. https://doi.org/10.1097/HJH. Ob013e3280dce59e.

25. Pechère-Bertschi $A$, Greminger $P$, Hess L, Philippe J, Ferrari P. Swiss hypertension and risk factor program (SHARP): cardiovascular risk factors management in patients with type 2 diabetes in Switzerland. Blood Press. 2005;14:337-44. https://doi.org/10.1080/08037050500340018.

26. Tsujimoto T, Sugiyama T, Shapiro MF, Noda M, Kajio H. Risk of cardiovascular events in patients with diabetes mellitus on beta-blockers. Hypertension (Dallas, Tex : 1979). 2017;70:103-10. https://doi.org/10.1161/ hypertensionaha.117.09259.

27. Matsuo S, Imai E, Horio M, Yasuda Y, Tomita K, Nitta K, et al. Revised equations for estimated GFR from serum creatinine in Japan. Am J Kidney Dis. 2009;53:982-92. https://doi.org/10.1053/j.ajkd.2008.12.034.

28. Staley JR, Jones E, Kaptoge S, Butterworth AS, Sweeting MJ, Wood AM, et al. A comparison of cox and logistic regression for use in genome-wide association studies of cohort and case-cohort design. Eur J Hum Genet. 2017;25:854-62.

29. Hellman B. The mechanism of sulfonylurea stimulation of insulin release. Acta Biol Med Ger. 1982:41:1211-9.

30. Drucker DJ, Nauck MA. The incretin system: glucagon-like peptide-1 receptor agonists and dipeptidyl peptidase-4 inhibitors in type 2 diabetes. Lancet. 2006;368:1696-705. https://doi.org/10.1016/S0140-6736(06)69705-5.
31. Yoon KH, Shin JA, Kwon HS, Lee SH, Min KW, Ahn YB, et al. Comparison of the efficacy of glimepiride, metformin, and rosiglitazone monotherapy in korean drug-naïve type 2 diabetic patients: the practical evidence of antidiabetic monotherapy study. Diabetes Metab J. 2011;35:26-33. https:// doi.org/10.4093/dmj.2011.35.1.26.

32. Salvo F, Moore N, Arnaud M, Robinson P, Raschi E, De Ponti F, et al. Addition of dipeptidyl peptidase-4 inhibitors to sulphonylureas and risk of hypoglycaemia: systematic review and meta-analysis. BMJ (Clinical research ed). 2016;353:i2231. https://doi.org/10.1136/bmj.i2231.

33. Inagaki N, Iwakura T, Iwamoto $Y$, Kadowaki T, Seino S, Seino Y. The committee regarding to adequate use for incretin-based therapy; 2010. https://www.nittokyo.or.jp/modules/information/index.php?content_id=19.

34. Bethel MA, Engel SS, Stevens SR, Lokhnygina Y, Ding J, Josse RG, et al. Progression of glucose-lowering diabetes therapy in TECOS. Endocrinol Diabetes Metab. 2019;2:e00053. https://doi.org/10.1002/edm2.53.

35. Teljeur C, Smith SM, Paul G, Kelly A, O'Dowd T. Multimorbidity in a cohort of patients with type 2 diabetes. Eur J Gen Pract. 2013;19:17-22. https://doi. org/10.3109/13814788.2012.714768.

36. Tsujimoto T, Sugiyama T, Kajio H. Effects of $\beta$-blockers on all-cause mortality in patients with type 2 diabetes and coronary heart disease. Diabetes Obes Metab. 2017;19:800-8. https://doi.org/10.1111/dom.12878.

37. Fihn SD, Blankenship JC, Alexander KP, Bittl JA, Byrne JG, Fletcher BJ, et al. 2014 ACC/AHA/AATS/PCNA/SCAI/STS focused update of the guideline for the diagnosis and management of patients with stable ischemic heart disease: a report of the American College of Cardiology/American Heart Association task force on practice guidelines, and the American Association for Thoracic Surgery, preventive cardiovascular nurses association, Society for Cardiovascular Angiography and Interventions, and Society of Thoracic Surgeons. J Am Coll Cardiol. 2014;64:1929-49. https://doi.org/10.1016/j.jacc. 2014.07.017.

38. Sanon VP, Sanon S, Kanakia R, Yu H, Araj F, Oliveros R, et al. Hypoglycemia from a cardiologist's perspective. Clin Cardiol. 2014;37:499-504. https://doi. org/10.1002/clc.22288.

39. Shavadia JS, Zheng Y, Green JB, Armstrong PW, Westerhout CM, McGuire DK, et al. Associations between $\beta$-blocker therapy and cardiovascular outcomes in patients with diabetes and established cardiovascular disease. Am Heart J. 2019;218:92-9. https://doi.org/10.1016/j.ahj.2019.09.013.

40. Malik AH, Shetty S, Kar K, El Accaoui R. Effect of $\beta$-blocker therapy in diabetic patients with stable coronary heart disease: a meta-analysis. J Geriatr Cardiol. 2019;16:291-7. https://doi.org/10.11909/j.issn.1671-5411.2019. 03.008.

41. Davis SN, LE M, Younk LM. Hypoglycemia and hypoglycemic syndromes. Endocrinology: adult and pediatric. 7th ed; 2016.

42. Chan JC, Cockram CS, Critchley JA. Drug-induced disorders of glucose metabolism. Mech Manage Drug Saf. 1996;15:135-57. https://doi.org/10. 2165/00002018-199615020-00005

43. Himwich HE. A review of hypoglycemia, its physiology and pathology, symptomatology and treatment. Am J Dig Dis. 1944;11:1.

44. M G, W B, Stevens. Sympathetic neurotransmission and adrenoceptor agonists. Brenner Stevens' Pharmacol. 2018;1:81-92.

45. Hoffmann C, Leitz MR, Oberdorf-Maass S, Lohse MJ, Klotz KN. Comparative pharmacology of human beta-adrenergic receptor subtypes-characterization of stably transfected receptors in $\mathrm{CHO}$ cells. Naunyn Schmiedeberg's Arch Pharmacol. 2004;369:151-9. https://doi.org/10.1007/ s00210-003-0860-y.

46. Casiglia $\mathrm{E}$, Tikhonoff $\mathrm{V}$. Long-standing problem of $\beta$-blocker-elicited hypoglycemia in diabetes mellitus. Hypertension (Dallas, Tex : 1979). 2017; 70:42-3. https://doi.org/10.1161/HYPERTENSIONAHA.117.09378.

47. Gerich JE, Langlois M, Noacco C, Schneider V, Forsham PH. Adrenergic modulation of pancreatic glucagon secretion in man. J Clin Invest. 1974;53: 1441-6. https://doi.org/10.1172/JCl107692.

48. Fonseca VA. Effects of beta-blockers on glucose and lipid metabolism. Curr Med Res Opin. 2010;26:615-29. https://doi.org/10.1185/03007990903533681.

\section{Publisher's Note}

Springer Nature remains neutral with regard to jurisdictional claims in published maps and institutional affiliations. 